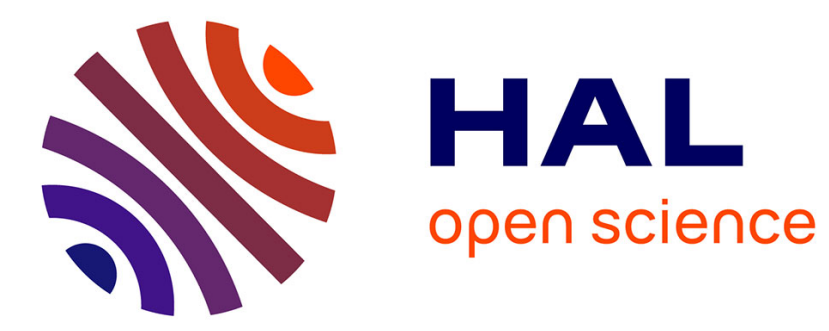

\title{
Low temperature low voltage operation of HEMTs on InP
}

\author{
A. Sylvestre, P. Crozat, R. Adde, A. de Lustrac, Yun Jin
}

\section{To cite this version:}

A. Sylvestre, P. Crozat, R. Adde, A. de Lustrac, Yun Jin. Low temperature low voltage operation of HEMTs on InP. Journal de Physique IV Proceedings, 1994, 04 (C6), pp.C6-153-C6-158. 10.1051/jp4:1994624 . jpa-00253118

\section{HAL Id: jpa-00253118 https://hal.science/jpa-00253118}

Submitted on 1 Jan 1994

HAL is a multi-disciplinary open access archive for the deposit and dissemination of scientific research documents, whether they are published or not. The documents may come from teaching and research institutions in France or abroad, or from public or private research centers.
L'archive ouverte pluridisciplinaire HAL, est destinée au dépôt et à la diffusion de documents scientifiques de niveau recherche, publiés ou non, émanant des établissements d'enseignement et de recherche français ou étrangers, des laboratoires publics ou privés. 


\title{
Low temperature low voltage operation of HEMTs on InP
}

\author{
A. Sylvestre, P. Crozat, R. Adde, A. De Lustrac and Y. Jin* \\ IEF, URA 22 du CNRS, Bât. 220, Université Paris-Sud, 91405, Orsay, France \\ * L2M/CNRS LP20, 196 rue de Ravera, 92220 Bagneux, France
}

\begin{abstract}
Pseudomorphic single recessed $\mathrm{Al}_{.48} \mathrm{In}_{.52} \mathrm{As} / \mathrm{Ga} .30 \mathrm{In} .70 \mathrm{As} / \mathrm{AlInAs}$ pseudomorphic HEMTs (PM-HEMT) on InP with planar doping and gatelength $0.2 \mu \mathrm{m}$ are investigated at cryogenic temperatures $(50 \mathrm{~K})$ for their high frequency intrinsic transport properties at low drain bias voltage. Transient drain current measurements are compared with DC characteristics and show the evolution of trapping effects versus drain voltage. HF measurements show that at low temperature drain current saturates at drain voltage as low as $0.5 \mathrm{~V}$ with nearly maximum transconductance $(\approx 800 \mathrm{mS} / \mathrm{mm})$ and very high intrinsic cut-off frequency $(\approx 190 \mathrm{GHz})$. In these ultrashort gate HEMTs, cryogenic temperatures bring the best relative improvement of intrinsic device transport properties $(\approx 60 \%)$ at very low drain voltages $(0.5 \mathrm{~V})$.
\end{abstract}

\section{Introduction}

Very high frequency transconductances and cut-off frequencies have been obtained in nanometer gatelength pseudomorphic HEMTs on InP at room temperature[1]. The larger band discontinuities and better carrier confinement result in superior device performances. Anomalous characteristics and associated with deep-level traps have also been investigated [2-3] relatively to optoelectronic applications at $300 \mathrm{~K}$. We have shown recently that the high frequency performances of 50K cooled HEMTs on InP with gatelength in the $0.2 \mu \mathrm{m}$ range benefited from considerable carrier transport improvement compared to 300K operation [4]. Very low noise cryogenically-coolable amplifiers with lattice-matched HEMTs on InP have been reported at $18 \mathrm{~K}$ with noise temperature of $47 \mathrm{~K}$ at $70 \mathrm{GHz}$ [5], which is comparable to SIS receiver performance in this frequency range corresponding to the atmospheric window at $3 \mathrm{~mm}$ wavelength. Although progress in the epitaxial growth of these device multilayers have been made, the published results show that low temperature characteristics are still influenced by trapping centers and other detrimental effects. We emphasize here the operation of pseudomorphic HEMTs on InP in very low drain bias conditions ( $\leq 1 \mathrm{~V})$ at low temperatures from $300 \mathrm{~K}$ down to $50 \mathrm{~K}$. We present preliminary drain current transient measurements ranging from short times $(\approx 10 \mathrm{~ns})$ up to DC conditions which bring new informations on the effect of traps versus biases and temperature. They show that further progression in 
low temperature performances may be expected at low drain voltage $\left(V_{d s}=0.5 \mathrm{~V}-1 \mathrm{~V}\right)$. We describe first the device structure and the electrical characterizations. Then we discuss the evolution of DC, pulsed and HF electric parameters as a function of temperature, of drain and gate biases.

\section{Experimental conditions}

The device is an $\mathrm{Al} .48 \mathrm{In} .52 \mathrm{As} / \mathrm{Ga} .30$ In.70As/AlInAs pseudomorphic HEMT (PM-HEMT) on InP substrate (Fig.1). It consists on an InP substrate, a $2500 \AA \mathrm{Al}_{.48} \mathrm{In} .52 \mathrm{As}$ buffer layer, a $150 \AA$ n.i.d. Ga.30In.70As channel, a $40 \AA$ AlInAs spacer, a Si delta-doped $\left(4.510^{12} \mathrm{~cm}^{-3}\right)$, a $250 \AA$ n.i.d. $A l .48 \mathrm{In} .52 \mathrm{As}$ layer, and a $100 \AA \mathrm{Si}$ doped $\left(4.10^{18} \mathrm{~cm}^{-3}\right) \mathrm{Ga} .47 \mathrm{In} .53$ As cap layer. The gatelength is $0.2 \mu \mathrm{m}$, the gatewidth is $100 \mu \mathrm{m}$ and the source-drain separation is $2 \mu \mathrm{m}$. The gate structure is single recessed with no recess optimization on the drain side for high drain breakdown voltage. Electrode pads and mesa area are patterned optically, and the gate is e-beam patterned with JEOLJBX5DII.

\begin{tabular}{|c|c|c|c|}
\hline source & & & drain \\
\hline $100 \AA$ & Wois & & GalnAs $8 \mathrm{~cm}-3$ \\
\hline $250 \AA$ & & AlInAs & n.i.d. \\
\hline \multirow[t]{2}{*}{$40 \AA$} & $\triangle$ doped Si: & \multicolumn{2}{|c|}{$4.5 \mathrm{e} 12 \mathrm{~cm}-3$} \\
\hline & spacer & AllnAs & n.i.d. \\
\hline $150 \AA$ & channel & GalnAS & n.i.d. \\
\hline \multirow[t]{2}{*}{$2500 \AA$} & buffer & AllnAs & n.i.d. \\
\hline & substrate & $\ln P$ & \\
\hline
\end{tabular}

Fig. 1 Schematic device structure

All DC, transient and HF measurements are performed in the same cryogenic station with microwave coplanar picoprobes and optical access allowing sample illumination. The transient measurements use wide bandwidth coaxial components and impedance calibration structures, a 2ns rise time generator driving the HEMT drain voltage. Then drain current transients are measured on the time scale from $10 \mathrm{~ns}$ to $600 \mathrm{~ns}$. The temperature control of the cooled probes near the sample holder temperature, the in-situ RF full calibration at the HEMT temperature of operation using an OSTL procedure and a standard substrate at the same temperature, give accurate and reproducible $S$-parameter measurements up to $45 \mathrm{GHz}$, smooth $S$ parameter variations versus frequency, temperature and biases. These features allow a direct determination of the device current and power gains and an extraction of equivalent circuit parameters versus temperature. 


\section{Experimental results and discussion}

We first discuss the evolution of drain current amplitude versus time from transient to DC conditions in Fig.2-6. At $300 \mathrm{~K}$ the DC IV characts:ristics (not shown) present very small kink, and are rather insensitive to illumination. This corresponds to what is usually refered as a low trap density structure. The Fig.2 shows the DC IV characteristics at $130 \mathrm{~K}$. As the structure has not been optimized for large breakdown voltage, the $\mathrm{V}_{\mathrm{ds}}$ investigation is limited at $1.5 \mathrm{~V}$. The HP4142 supply corresponds to $\mathrm{a} \approx 1 \mathrm{~ms}$ acquisition time per point. The Fig. 2 shows for open channel conditions $\left(\mathrm{V}_{\mathrm{gs}} \approx-0.7 \mathrm{~V}\right.$ corresponds to maximum transconductance), a moderate kink effect occurs at $\mathrm{V}_{\mathrm{ds}} \geq 0.5 \mathrm{~V}$ due to trapping in the InAlAs layers. This trapping occurs mostly in the InAlAs buffer as some $I_{d s}$ collapse is visible at negative gate voltage $\left(\mathrm{V}_{\mathrm{gs}}=-1.3 \mathrm{~V}\right)$ near threshold. The amount of trapping in the InAlAs buffer would be smaller in HEMTs with the same epilayer structure and a deeper recess giving a less negative threshold voltage. Characteristics taken in three different illumination conditions (dark, medium light intensity of binocular white light illumination, full intensity) indicate a small influence of intensity illumination. However all characterizations have been performed under constant illumination to minimize trapping.

The Fig. 3-4 present $I_{d s}$ transient amplitudes at $\mathrm{T}=130 \mathrm{~K}$ as in Fig. 2 and at constant $\mathrm{V}_{\mathrm{gs}}$ bias versus $V_{d s}$ which is pulsed as described earlier. $I_{d s}$ amplitudes are presented at times $\mathrm{t}=10 \mathrm{~ns}$ and 600ns.

The IV characteristic corresponding to $t=10$ ns transients (Fig.3) does not show any visible anomaly in the $0.5 \mathrm{~V}$ drain region as it will be confirmed later in the corresponding transconductance (curve Fig 9). On the other side in the $I_{d s}$ curves at $t=600$ ns (Fig 4) some kink effect at small $V_{d s}$ is already observable. This verifies experimentally that part of electron capture is a fast process in the several tens nanoseconds. Besides Fig. 3 shows that some extra drain current appears at $V_{d s} \geq 0.8 \mathrm{~V}$ already 
at $\mathrm{t}=10 \mathrm{~ns}$ which amplitude grows further with time (see Fig.4 and Fig 2). We shall come back on this point when discussing the gate current evolution. Different time scales are apparent from the observation of Fig 2-4 and further time domain investigation is necessary to characterize them more accurately.

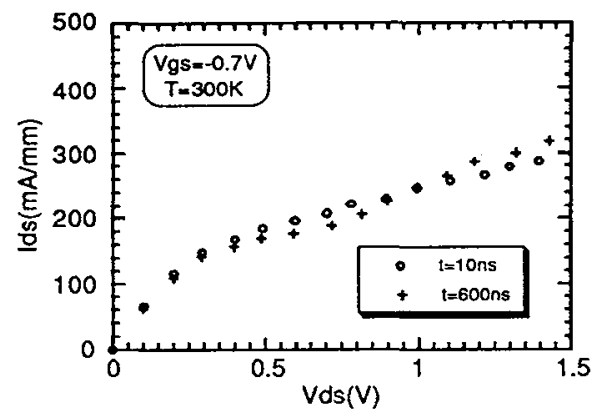

Fig 5 Transient Ids amplitude vs Vds at $t=10 \mathrm{~ns}$ and $600 \mathrm{~ns}(\mathrm{~T}=300 \mathrm{~K})$

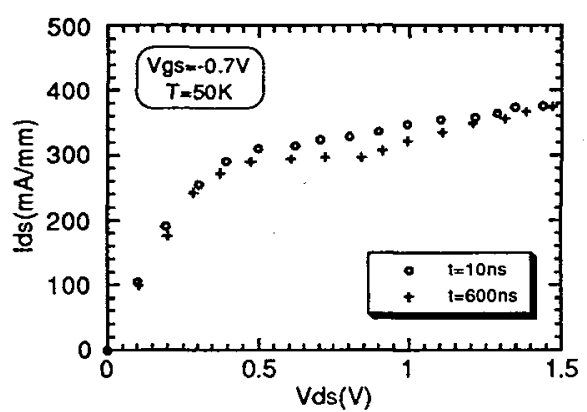

Fig. 6 Transient Ids amplitude vs Vds at $t=10 \mathrm{~ns}$ and $600 \mathrm{~ns}(T=50 \mathrm{~K})$

The Fig.5 and Fig. 6 complement Fig. 3 and Fig. 4 to show the $I_{\text {ds }}$ amplitude evolution with time versus temperature from $300 \mathrm{~K}$ down to $50 \mathrm{~K}$. They indicate that the $I_{d s}$ amplitude at $t=10 \mathrm{~ns}$ and $600 \mathrm{~ns}$ crossover at different $V_{\mathrm{ds}}$ depending on $\mathrm{V}_{\mathrm{gs}}$ and $\mathrm{T}$. It may be already said that at the larger $\mathrm{V}_{\mathrm{ds}}$ where $I_{d s}(t=10 n s)<I_{d s}(t=600 n s)$, both carrier detrapping and impact ionization contribute to the increase of $I_{d s}$ amplitude versus time.

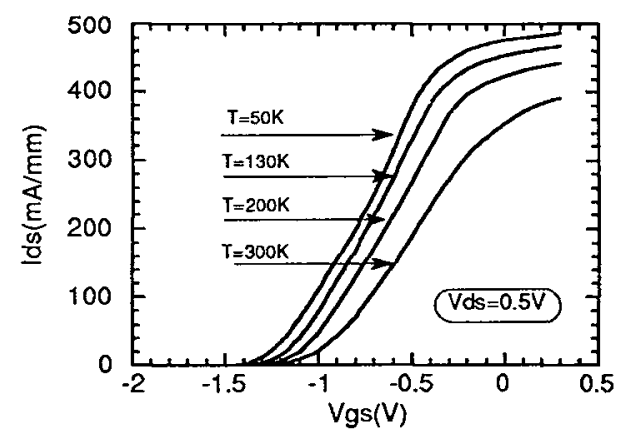

Fig. $7 I_{d s}$ versus $V_{g s}$ and temperature $\left(V_{d s}=0.5 \mathrm{~V}\right)$

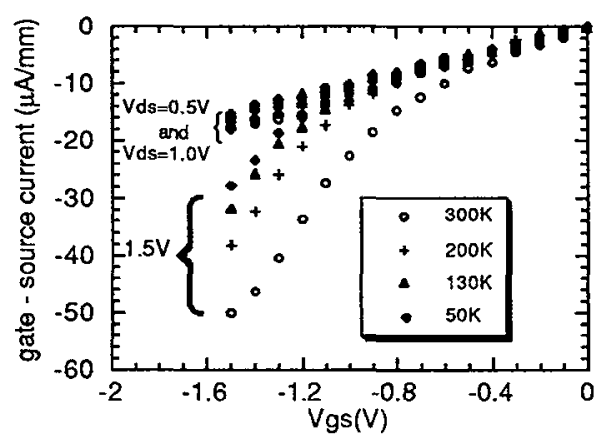

Fig. $8 I_{g s}$ versus $V_{g s}, V_{d s}$ and temperature

The Fig.7 presents the DC transfer characteristics $I_{d s}=f\left(V_{g s}\right)$ versus temperature at $V_{d s}=0.5 V . A$ more important $I_{d s m a x}$ at $50 \mathrm{~K}$ is obtained : $25 \%$ higher than $I_{d s m a x}$ at $300 \mathrm{~K}(480 \mathrm{~mA} / \mathrm{mm}$ vs $400 \mathrm{~mA} / \mathrm{mm})$. We can notice in Fig.7 a shift of the threshold voltage $\approx-0.2 \mathrm{~V}$ from $300 \mathrm{~K}$ to $50 \mathrm{~K}$. This shift is translated in the $\mathrm{V}_{\text {gs }}$ value corresponding to $\mathrm{G}_{\mathrm{mmax}}(-0.7 \mathrm{~V}$ at $50 \mathrm{~K}$ and $-0.5 \mathrm{~V}$ at $300 \mathrm{~K})$.

The evolution of gate current $I_{g s}$ is presented versus $V_{g s}$ in Fig. 8 at $V_{d s}$ values of $0.5 \mathrm{~V}, 1 \mathrm{~V}$ and $1.5 \mathrm{~V}$ versus temperature. At $0.5 \mathrm{~V}$ and $1 \mathrm{~V}$, all $\mathrm{I}_{\mathrm{gs}}$ data points lie along a continuous line at all temperatures from $300 \mathrm{~K}$ down to $50 \mathrm{~K}$. On the other side at $\mathrm{V}_{\mathrm{ds}}=1.5 \mathrm{~V}$ and gate voltage with strong pinch- 
off near threshold, the high energy of the carriers in the small-gap InGaAs channel create an additional gate current component which is associated with impact ionization. Fig.8 shows that at $\mathrm{V}_{\mathrm{ds}} \leq 1 \mathrm{~V}$ and low temperatures, $I_{g s} \leq 20 \mu \mathrm{A} / \mathrm{mm}$. Such a low value shows that the pseudomorphic structures with $\mathrm{In}=0.6$ are very promising for very low noise operation [5].

Access lines and device access resistances are extracted from $\mathrm{HF}$ measurements at a special bias condition $\left(\mathrm{V}_{\mathrm{ds}}=0 \mathrm{~V}, \mathrm{~V}_{\mathrm{gs}}=1 \mathrm{~V}\right)$ for each temperature. A coherent set of values is obtained for the whole temperature range (see Table 1). A precise line model including skin effect is used for the $100 \mu \mathrm{m}$ access line. Unlike the access line losses, access resistances $R_{\mathcal{S}}, R_{d}$ and $R_{g}$ experiment only a $50 \%$ decrease with temperature. This indicates that they include non metallic losses.

Table 1 : Temperature dependence of access elements

\begin{tabular}{|c|c|c|c|c|c|c|}
\hline $\begin{array}{c}\text { Temp } \\
\left({ }^{\circ} \mathrm{K}\right)\end{array}$ & $\begin{array}{c}\mathrm{R}_{\mathrm{S}} \\
(\Omega . \mathrm{mm})\end{array}$ & $\begin{array}{c}\mathrm{R}_{\mathrm{d}} \\
(\Omega . \mathrm{mm})\end{array}$ & $\begin{array}{c}\mathrm{R}_{\mathrm{g}} \\
(\Omega / \mathrm{mm})\end{array}$ & $\begin{array}{c}\text { Gate. access } \\
\text { Length }(\mu \mathrm{m})\end{array}$ & $\begin{array}{c}\text { Drain access } \\
\text { Length }(\mu \mathrm{m})\end{array}$ & $\begin{array}{c}\text { Access lines } \\
(\Omega / \mathrm{mm})\end{array}$ \\
\hline 300 & 0.35 & 0.4 & 240 & 87 & 90 & 18 \\
\hline 50 & 0.25 & 0.3 & 160 & 90 & 86 & 3.5 \\
\hline
\end{tabular}

The main HF parameters are presented versus $V_{g s}$ at $V_{d s}=0.5 \mathrm{~V}$ (Fig.9-10) and versus $V_{d s}$ (Fig.1112). An overall good agreement between modeling and measurement is obtained for all biases up to 40 $\mathrm{GHz}$. Extrinsic transconductance determined from HF extracted equivalent circuit compares favorably with DC tranconductance (Fig 9) which confirms the small influence of traps at $V_{d s}=0.5 \mathrm{~V}$. The DC extrinsic transconductance exhibits a maximum value $\mathrm{G}_{\mathrm{mmax}}$ of $600 \mathrm{mS} / \mathrm{mm}$ and $440 \mathrm{mS} / \mathrm{mm}$ at $\mathrm{V}_{\mathrm{ds}}=0.5 \mathrm{~V}$ for the temperatures $50 \mathrm{~K}$ and $300 \mathrm{~K}$ respectively. The current density under the $\mathrm{G}_{\mathrm{mmax}}$ condition is $280 \mathrm{~mA} / \mathrm{mm}(50 \mathrm{~K})$ and $100 \mathrm{~mA} / \mathrm{mm}(300 \mathrm{~K})$. The increase of the transconductance at low temperature indicates a better gate control of the current and a possible increment of the average carrier velocity. Intrinsic cut-off frequency versus $\mathrm{V}_{\mathrm{gs}}$ (Fig.10) follows closely the evolution of transconductance with a slight maximum shift towards negative $\mathrm{V}_{\mathrm{gs}}$ due to capacitance increase with gate voltage.

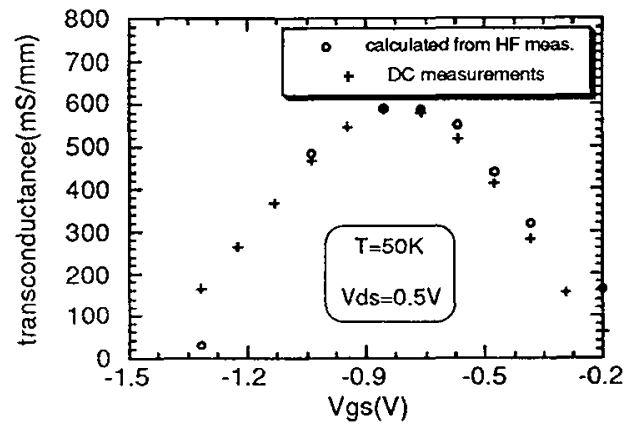

Fig. $9 \mathrm{G}_{\mathrm{mext}}$ versus $\mathrm{V}_{\mathrm{gs}}$ at $50 \mathrm{~K}$

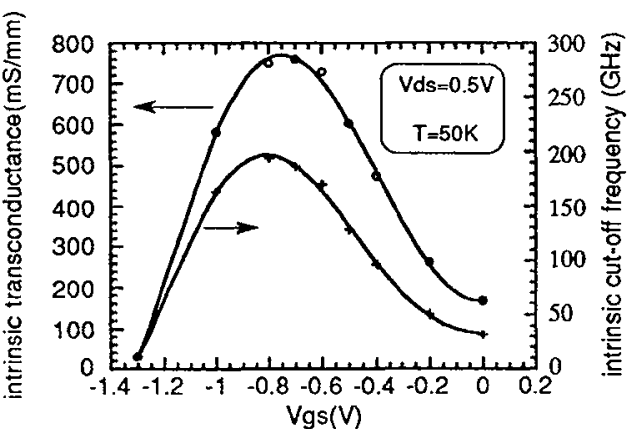

Fig. $10 F_{\text {tin }}$ and $G_{\operatorname{mint}}$ versus $V_{g s}$ at $50 \mathrm{~K}$ 
We now focus on evolution of $G_{\operatorname{mint}}$ and $F_{\text {tin }}$ versus $V_{d s}$ (Fig.11-12). Fig.11 shows the evolution of intrinsic transconductance $G_{\operatorname{mint}}$ versus $V_{d s}$ at optimum $V_{g s}$ bias $(\approx-0.7 \mathrm{~V})$. This $\mathrm{G}_{\operatorname{mint}}$ reaches $800 \mathrm{mS} / \mathrm{mm}$ at $50 \mathrm{~K}$ for $V_{d s}=0.5 \mathrm{~V}$ and does not increase more than $5 \%$ beyond this value. The large increase of $\mathrm{G}_{\mathrm{mint}}$ at $\mathrm{V}_{\mathrm{ds}}=0.5 \mathrm{~V}$ reflects the improvement of carrier transport under the gate largely related to the increase of average carrier velocity which at low temperature is primarily due to higher mobility in the low field region of the device.

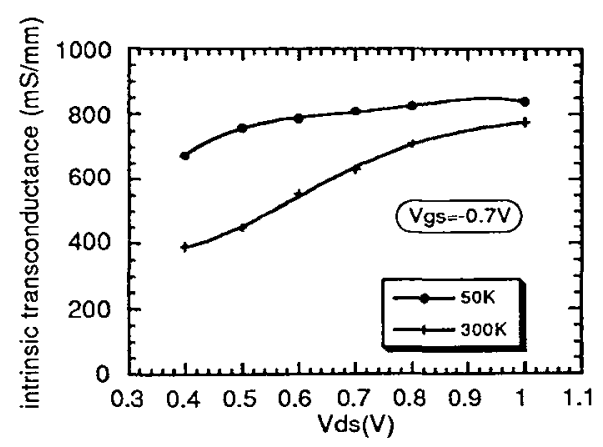

Fig. $11 G_{\text {mint }}$ versus $V_{d s}$ at $50 \mathrm{~K}$ and $300 \mathrm{~K}$

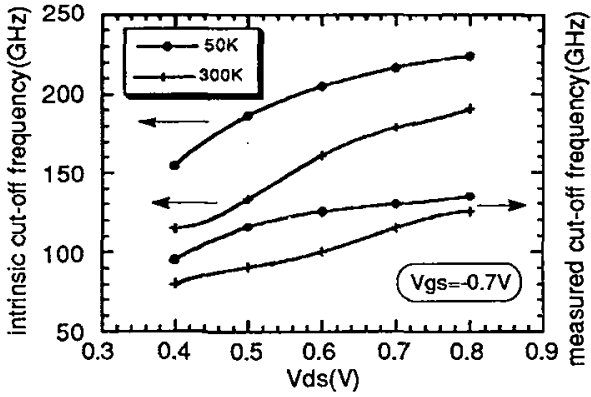

Fig. 12 Ftin and $F_{\text {tmeas }}$ versus $V d s$ at $50 \mathrm{~K}$ and $300 \mathrm{~K}$

Intrinsic cut-off frequency $F_{t i n}=G_{\min } /\left(2 \pi\left(C_{g s}+C g d\right)\right)$ and extrapolated ( $6 \mathrm{~dB}$ /octave slope) cut-off frequency $F_{\text {tmeas }}$ are presented in Fig. 12. The large difference between intrinsic and measured $F_{\text {tin }}$ (30\% at $300 \mathrm{~K}$ and $50 \%$ at $50 \mathrm{~K}$ ) is partly related to a high value of output conductance which increases at low temperature. $F_{\text {tin }}$ steadily increases with $V_{d s}$, but is only below $20 \%$ of its maximum value at $V_{d s}=0.5 \mathrm{~V}$.

The device has attractive intrinsic tranconductance near $800 \mathrm{mS} / \mathrm{mm}$ and cut-off frequency $\mathrm{f}_{\text {tin }}$ near $190 \mathrm{GHz}$. This illustrates that at cryogenic temperatures, HEMTs on InP have good intrinsic properties for high frequency performances at very low drain bias.

The authors are indebted to Dr. Linh and Dr. Rochette from PICOGIGA for the epitaxial layers.

\section{References}

[1] L.D. Nguyen, A.S. Brown, M.A. Thompson and L.M. Jelloian,"50-nm self-aligned-gate pseudomorphic AlInAs/GaInAs high electron mobility transistors", IEEE Trans. Elect. Devices, vol.39, pp.2007-2014, 1992.

[2] C. Heedt, F. Buchali, W. Prost, D. Fritzsche, H. Nickel, F.J. Tegude,"Characterization of impactionization in InAlAs/InGaAs/InP HEMT structures using a novel photocurrent-measurement technique", Indium Phosphide and Related Materials Vth Conf., Paris, pp.247-250, 1993.

[3] W. Kruppa and J.B. Boos,"Sinusoidal and transient response of traps in double-recessed InAlAs/InGaAs/InP HEMTs, same IPRM Conf., Paris, pp.251-254, 1993.

[4] A. Sylvestre, P. Crozat, R. Adde, A. De Lustrac, Y. Jin, J.C. Harmand, M. Quillec, Cryogenic investigation of gate leakage and RF performances doqn to $50 \mathrm{~K}$ of $0.2 \mu \mathrm{m}$ AlInAs/InGaAs/InP HEMTs", Elect. Lett., vol.29, pp.2152-54, 1993.

[5] M.W. Popieszalski, W.J. Lakatosh, R. Lai, K.L. Tan, D.C. Streit, P.H. Liu, R.M. Dia, J. Velebir, "Millimeter-wave cryogenically-coolable amplifiers using AlInAs/GaInAs/InP HEMTs", IEEE MTT Symposium Digest, pp.515-518, 1993. 